\title{
6
}

\section{The semantics of bushfire in Australian English}

\author{
Helen Bromhead
}

\section{Introduction}

Australian English can act as a mirror of conceptualisations of and attitudes towards extreme weather and climate events in the country, such as bushfires, drought, cyclones and floods. ${ }^{1}$ This variety of English encodes specific local meanings; for example, in the domain of landscape, words like creek and bush have particular senses in Australian English (Arthur 2003; Bromhead 2018). Bushfire is an Australian word for an uncontrolled fire in dry trees and shrubs, an event that can threaten homes and people, as well as vegetation and wildlife. The word could be seen as analogous to wildfire as used in North American English for forest fires. ${ }^{2}$ However, this would be to misunderstand the semantic content brought by the component bush. This chapter provides a rigorous

\footnotetext{
1 Many thanks to Zhengdao Ye, James Grieve and two anonymous reviewers for helpful comments on this chapter. I am grateful to Anna Wierzbicka and Jock Wong for workshopping of the semantic explication of bushfire. Participants at the Workshop on NSM Semantics and Mimimal English, The Australian National University, 15-16 April 2019, provided useful feedback.

2 Wildfire is not nearly as common in Australian English as bushfire. While there are 249 occurrences of the lemma bushfire, bush fire and bush fires in the Australian material of the Collins Wordbanks corpus, there are 35 of the lemma wildfire, wild fire and wild fires. Of these only 15 refer to events in Australia.
} 
semantic analysis of bushfire, discusses the term's status as a cultural keyword in Australian English and offers a cultural script of Australian practices surrounding bushfires.

Employing the Natural Semantic Metalanguage (NSM) approach to semantic and conceptual analysis (Wierzbicka 1985, 1996; Goddard and Wierzbicka 2014; Ye 2017), the cultural scripts approach to the analysis of cultural practices and values (Wierzbicka 2003; Goddard 2006) and drawing on literature on cultural keywords (Wierzbicka 1997; Levisen and Waters 2017a), the study is assisted by corpus-based collocational analysis. Discussion draws on environmental communication, environmental history, community bushfire information, news reports and survivor accounts, which are referred to in the chapter. The chapter provides a starting point for showing how semantic analysis and cultural scripts can help to capture the varying, conflicting and evolving assumptions about climate and extreme weather, influenced by factors such as climate change and increased understanding of Indigenous knowledge in Australia.

The chapter begins with an overview of extreme weather and climate event vocabulary as a domain, and the possible status of bushfire as a cultural keyword in Australian English. It then moves to provide an analysis of bushfire, discussing the examples used and meaning components, then providing a semantic explication and a bushfire-related cultural script. The chapter concludes with a discussion of the prospects for semantic analysis of extreme weather and climate event words, including bushfire, and the writing of cultural scripts pertaining to these events.

\section{The semantic domain and cultural keywords}

Extreme weather and climate events have played a role in the shaping of settler Australian history and national identity since Australia was colonised by Britain (e.g. West 2000; Sherratt et al. 2005). NonIndigenous Australians have had to deal with a climate prone to events such as droughts, floods and bushfires, different from that in lands from which they, or their ancestors, came, and try to come to terms with what Indigenous people already knew about the Australian environment (e.g. Gammage 2011; Barton and Bennett 2013; Pascoe 2014). Battling 
nature's elements and helping affected communities are seen as central to an Australian cultural ethos, which is both valorised and contested. The climate emergency increases the likelihood of extreme weather events in Australia, such as heatwaves and, the focus of the chapter, bushfires (CSIRO-BOM 2018). Australian English discourse in mainstream and social media often draws a connection between these kinds of events and the need for political action to address climate change (e.g. Hackett et al. 2017; Flanagan 2019).

Extreme weather and climate events in Australia have been studied from the point of view of disciplines including meteorology, history, sociology, public health, community safety and environmental communication (e.g. Webb 1997; Morrissey and Reser 2007; Handmer and Haynes 2008; Leitch and Bohensky 2014), yet consideration of the semantics of terms like bushfire and cyclone, and their possible status as Australian cultural keywords, remains unexplored. Australians have a number of options as to what to call a period without rain, such as drought, dry season and El Niño event. ${ }^{3}$ When they either select a term to use, or encounter the word in discourse, different ideas about the Australian climate are revealed. Drought evokes a natural disaster, dry season an expected happening, and El Niño event a circumstance that comes about due to global factors. Pinning down the precise senses of words of these kinds and their associated cultural scripts sheds light on conceptualisations of the Australian environment. This chapter uses the case of the word bushfire as a way to begin exploring the semantic domain.

A brief word on the cultural and geographic context of bushfires in Australia is in order. Bushfires are more likely during the hotter, drier months of summer in many regions of Australia, and spread more easily in winds. They burn in 'bush', a mass noun denoting vegetation, dominated by eucalypts, as an undifferentiated mass (Bromhead 2011, 2018). Fire is a natural part of some Australian ecosystems; a majority of Australia's plant species either need or tolerate fire (Gammage 2011). Aboriginal people used fire as a tool, in part, to manage vegetation growth and prevent severe uncontrolled fires, practices that continue in some places today (AWNRMB-DEWNR 2014). Somewhat similar burning regimes have been adopted by Australian government bodies as part of

3 Swings in rainfall in Australia are associated with an atmospheric event involving the Southern Oscillation, part of a global system of ocean-atmosphere interaction. Also involved are temperature variations in the eastern Pacific Ocean known as El Nińo (Whetton 1997: 189). 
bushfire prevention (Pyne 2006). Although fire may be a natural part of the Australian environment, uncontrolled fires in bush constitute natural hazards that threaten vegetation, wildlife, homes and people's lives, and are therefore culturally significant and have affordances in discourse (see Enfield 2008).

Bushfire could be considered an Australian cultural keyword. Drawing on Anna Wierzbicka's pioneering Understanding Cultures through their Key Words (1997), Levisen and Waters (2017b) write that cultural keywords 'govern the shared cognitive outlook of speakers and encode certain culture-specific logics, and impose on their speakers a certain interpretative grid through which they make sense of the world' (2017b:3). In Bromhead $(2011,2018)$, I presented the bush as a cultural keyword in Australian English and touched on its productivity in the formation of compounds, one of which is bushfire. This word, also, has an amount of associated phraseology too vast to detail in any depth (see also Arthur 2003: 147-50). Bushfire-related vocabulary can range from scientific concepts, such as fuel load, to community safety terms, such as bushfire survival plan, to Aboriginal land management practices, as in caring for country with fire, to informal language, such as firies for firefighters, or even vollie firies for volunteer firefighters (see Wierzbicka 1986, 1992 on colloquial 'depreciatives').

The meaning of bushfire brings with it the meaning of the Australian word for an undifferentiated mass of dry vegetation, bush (Bromhead 2011, 2018). A crucial point of that meaning is 'dry'-Australians expect that bush is likely to burn. This local Australian English meaning of the word bushfire can help explain why people feel especially confronted by fires burning in rainforest, which is not the canonical Australian bush.

The significance of bushfires to the psyche of Australians can be seen by the attribution of names for some major bushfires, such as Ash Wednesday (Victoria and South Australia, 1983). The fact that many Australians know the names of the American water-bombing aircraft used to fight bushfires in the Australian summer, such as Elvis, is indicative (Caruana 2012). Further, native animals that have survived bushfires become symbols of community resilience, such as Lucky the koala, found severely injured after the 2003 Canberra bushfires (Doherty 2008). Keyword status can also be seen in semiotic phenomena other than language (Levisen and Waters 2017b: 7-8). The multicoloured, adjustable fire danger rating signs that appear along many Australian roads (Campbell 2017), and other bushfire 
awareness signs, constitute examples of visual discourse about bushfires in place, experienced by many Australians as they drive (see Scollon and Scollon 2003 on discourses in place, also Jaworski and Thurlow 2010). In what follows, I explore the semantics of this cultural keyword and give a cultural script of Australian practices concerning bushfires.

\section{Bushfire examples used}

My study of the bush (Bromhead 2011, 2018) was assisted by corpus analysis of the Australian English Oznews subcorpus of Collins Wordbanks of English, ${ }^{4}$ a relatively small corpus of Australian English, but one of the most suitable (see Ye, this volume). As part of this corpus assistance, a word sketch, a summary of a word's collocational behaviour sorted via grammatical relations and based on statistical significance, was used to find representative examples and indicative collocates. Such analysis is trickier for bushfire. The examples of bush in the corpus are far more numerous than those of bushfire and bush fire. In the Australian material of Wordbanks, 235 instances of the lemma bushfire appear (a frequency of 6.44 per million words), and 14 of bush fire or bush fires (a frequency of 0.38 per million).

The word sketch of the lemma bushfire reveals collocational behaviour, yet some data may not be sufficiently robust. For example, the most statistically significant collocate of which bushfire is a subject is ravage; however, this is based on only one token in the corpus. By contrast, claim is the fourth most significant subject collocate, and this is based on a more robust five tokens. The chapter uses significant collocations as evidence of the semantics of bushfire (see Andrews 2016: 98 and $n 11$ on the use of collocations in NSM analysis). One token with statistical significance can tell us something. All collocations taken from the word sketch based on token counts smaller than five have been checked in an $\mathrm{ABC}$ (Australian Broadcasting Corporation) news search to ensure that they in fact do occur more widely. ${ }^{5}$ For example, a search of bushfire with the verb ravage yields many results, so this collocate is taken as indicative. On the other hand, afternoon is a significant collocate based on two tokens, but it is not attested on $\mathrm{ABC}$ news, so it is not mentioned. Unless otherwise indicated,

4 Searched at: wordbanks.harpercollins.co.uk.

5 Searched at: www.abc.net.au/news. 
all examples used in the chapter are taken from Australian material in Wordbanks. The analysis of bushfire in this chapter can be seen as assisted by a corpus as opposed to corpus-driven (McEnery and Hardie 2011).

\section{Evidence from use}

Bushfires are events situated in particular kinds of places. These must be places that span some distance, and in which a certain vegetation type grows, what can be described in Australian English as bush. Not all fires that take place in the natural environment can be classed as bushfires. There is also the category of a grass fire, often a less serious event, which takes place over a smaller area and has a different fuel source. An example of use of bushfire adduced by The Australian National Dictionary (AND) reads:

(1) 'You ever seen a bush fire?' 'Not a real one ... just grass fires in a paddock.' (John Cleary, The Sundowners, 1952, in AND 2016)

While a particular type of vegetation is present, places in which bushfires occur are not necessary counted as being 'the bush'. The bush is a polysemous term, and two of its senses particularly pertinent to this discussion I delineated in Bromhead $(2011,2018)$. One meaning of this bush is a kind of Australian folk biological zone. This meaning of the bush conveys not just that the vegetation type, 'bush', grows there, but also the presence of uniquely Australian wildlife, the nature of it as a place where not many people live and the fact that one may not see many people there. Another relevant meaning is the bush is zone where people can live-these places are outside major cities and near 'the bush' as a biological zone. A Queensland state government extreme weather events safety website 'Get Ready Queensland' writes the following about bushfires in (2):

(2) You don't have to live in the bush to be threatened by bushfireyou just have to be close enough to be affected by burning material, embers and smoke. (Get Ready Queensland n.d.)

For example, the western suburbs of Canberra affected by a bushfire in 2003 could not be described as being part of the bush, either as the bush as a biological zone (the first the bush sense mentioned above), or the bush as a place in Australia opposed to the city (the second the bush sense mentioned above). 
Bushfires occur at hot, dry times of year. Bushfire collocates with season, the most numerous of all the significant collocates of which bushfire is a modifier, as in (3).

(3) The Queensland bushfire season lasts from August to December ...

A bushfire is unwanted. Burning undertaken by people as a way of reducing fire fuel can be described as burning off, controlled burns and prescribed burns, which are part of the associated phraseology (see (4)). Yet no matter how big these fires, they could not be called bushfires, unless they were to move beyond the control of those undertaking them.

(4) What would you do to prevent fires like the one that devastated Canberra? You need deliberate prescribed burns ...

In the main, bushfires are caused by lightning strikes or, unfortunately, deliberately lit (Muller and Bryant 2008). Arson and arsonist appear as significant collocates modified by bushfire in a word sketch (as in (5)), and light also appears as a significant verb collocate in examples that refer to arson.

(5) ... as a Government we have doubled the penalties for bushfire arson ...

Many collocates of bushfire pertain to the nature of fire, such as flare (see (6)), rage, burning and smoke. The movement of bushfires can be described by saying that bushfires rip and sweep across areas (see (7)), and a bushfire can have a path.

(6) Hundreds of people ... were evacuated after the bushfire flared at lunchtime.

(7) More than 400ha have been burnt, with the bushfire sweeping from the residential hills fringe suburb $\ldots$ to the Cleland Conservation Park ...

Bushfires are significant because of the destruction they wreak on bushland, animals, people's houses and the person. Numerous collocates reflect this destructive nature, such as the verbs claim and ravage (see (8)), the adjectives deadly, devastating and bad (see (9)), and the nouns emergency, horror, catastrophe, hazard, danger, disaster, casualty, destruction and victim as in (10). 
(8) When bushfire has ravaged a farm ...

(9) South Australia's worst bushfire in 22 years was simply impossible to control.

(10) Governor Marjorie Jackson-Nelson was on the Eyre Peninsula ..., visiting bushfire victims.

Looking at a selection of Australian television news reports of bushfires in videos uploaded to YouTube, one sees that the effects of bushfires are measured by their impact on people, houses and land, as in (11).

(11) Thirty-six homes have been destroyed and over 30,000 hectares of national park have gone up in smoke as massive fires roar through the territory. News just at hand of unconfirmed reports of at least one fatality and several burns victims being flown to the Canberra hospital. ('Canberra firestorm news coverage' 2019: 2:03-2:12)

However, a bushfire need not necessarily destroy homes and threaten people's lives. Example (12) gives a definition of a bushfire from Australia law.

(12) The Criminal Law Consolidation Act 1935 ... defines a bushfire as 'a fire that burns, or threatens to burn, out of control causing damage to vegetation (whether or not other property is also damaged or threatened)'.

A bushfire leaves a characteristic burnt, black landscape in its wake. The documentary Rising From The Ashes, in part, depicts the devastated Victorian landscape after the Black Saturday bushfires of 2009. In (13), a bushfire survivor tells of the visual experience after the fire on his property.

(13) Immediately after the fire, you couldn't see any green at all. All of that was just black. (Rising From The Ashes (2018): 2:37-2:43)

The evidence from collocations and examples discussed in this section can be used to capture the meaning of bushfire in a semantic explication. 


\section{A semantic explication of bushfire}

As is the case for all NSM conceptual analysis, this study employs a humancentred perspective (see especially Wierzbicka 1989; for reflection, see Newman, this volume, Allan, this volume). Like geographic concepts, such as mountain and the bush (Bromhead 2018), there are human interests in extreme weather and climate events, such as bushfire. Sherratt (2005: 2) cites the American historian of weather, David Laskin (1996: $3-4)$, writing 'weather "doesn't just happen ... it happens to us"'. These human interests make their way into analysis of bushfire not only via the effect of bushfires on people and the places where they live, but also by way of concepts such as 'bush' and 'fire', which contain human elements in their semantics. The following explication [A] presents the sense of bushfire. Its components are structured as follows: places, what happens, very bad things can happen and what a place is like after it happens.

\section{[A] semantic explication of bushfire (Australian English)}

\section{[PLACES]}

a. something bad can happen in places of some kinds

places of these kinds are very big, they have many parts

there is a lot of bush ${ }_{1}[\mathrm{~m}]$ in these places

at some times, there can be very little water $[\mathrm{m}]$ in some parts of these places

[WHAT HAPPENS]

b. when it happens in a place, it is like this:

there is a big fire $[\mathrm{m}]$ in this place not because people want it something bad is happening to the bush [m] in this place for some time because of this

it is burning $[\mathrm{m}]$, it happens like this:

fire $[\mathrm{m}]$ moves quickly $[\mathrm{m}]$ in this place because the wind $[\mathrm{m}]$ is moving quickly $[\mathrm{m}]$ in this place

if it is in one part of this place at one moment, a short time after this it can be in another part

there is a lot of smoke $[\mathrm{m}]$ in this place 
[VERY BAD THINGS CAN HAPPEN]

C. when something like this happens in a place, it can be like this:

very bad things can happen to many parts of this place

very bad things can happen to the bush $[\mathrm{m}]$ in this place

very bad things can happen to the creatures $[\mathrm{m}]$ in this place, they can die

very bad things can happen to people in this place, they can die very bad things can happen to the places where people live in this place

[WHAT A PLACE IS LIKE AFTER IT HAPPENS]

d. after something like this happens in a place, this place is not like it was before

when someone sees this place, they can think like this:

'something bad happened to the bush [m] in this place

as happens to wood [m] if fire $[\mathrm{m}]$ touches it for some time.'

Section (a) of the explication of bushfire presents the places in which a bushfire happens. They are very big, composed of many parts, and there is a lot of bush in these places. The semantic molecule 'bush', as in bush as a vegetation type, not as a kind of place (the bush), appears. This molecule brings with it the sense of dry vegetation as a mass, indigenous to Australia and in its natural state (see Bromhead 2011, 2018, for a semantic explication). The fact that bushfire occurs in places where at times there is little water in a place is also conveyed.

Section (b) depicts what happens-a bushfire is an event. The molecule 'fire', naturally, is used (see Wierzbicka 1996: 223; Goddard 2010: 141-42). This fire is big and unwanted by people. Bushfires caused by arson were mentioned previously. The component 'not because people want it' still holds in such cases; an arsonist, 'someone', may desire the fire, but 'people' in general do not. The destruction of bush is portrayed. The movement of the fire as a result of wind, and the presence of smoke, is also treated.

Components in section (c) address the very bad things that happen as a result of bushfire. Damage to parts of places, to the vegetation (the bush), to creatures (even to death), to people (even to death) and to places where people live are covered. 
Section (d) portrays the characteristic burnt landscape following a bushfire. This is represented through human vision and the thought that fire has occurred.

\section{Human responses to bushfire in Australian English: A cultural script}

The response of humans to bushfires is a significant part of the discourse around the word. Extensive efforts go to fighting bushfires and, as previously touched on, these efforts are seen as shaping the nation's psyche. Significant verb collocates of bushfire are fight and battle (see (14)). Professional fire brigades are supplemented by a large number of volunteer firefighters. The word sketch attests the significant collocations volunteer bushfire fighters (see (15)) and bushfire brigade.

(14) Fire crews are still battling a bushfire at Bicheno ...

(15) ... volunteer bushfire fighters, a national resource too easily taken for granted ...

Furthermore, battling bushfires is too large a matter to be solely dealt with by dedicated fire brigades, who often focus on attacking the fires in a systematic way and protecting government assets, leaving the defence of individual houses to their occupants. Householders are urged to prepare for bushfires by drafting a bushfire survival plan, and by reducing hazards, such as by clearing gutters of leaves (see e.g. 'Get Ready Queensland' website). At a government level, the aforementioned prescribed burns are carried out in preparation for bushfire season.

Australians pride themselves on helping one another after a disaster, as seen in folk belief and in political discourse following disastrous extreme weather events, and this ties in with a national ethos of solidarity (e.g. West 2000; Rudd 2009; Rowan 2017: 76-77, n12). The idea that Australians have a particular distinction in providing community assistance after disaster has been disputed; it has also been pointed out that this assistance can be subject to racial and class inequities (e.g. Fisher 2011). This community assistance is reflected in the corpus, in which bushfire appeal is a significant collocation, as in (16). 
(16) Real estate agents ... will have a monster auction ... to raise money for the bushfire appeal.

Bushfires are events from which people often try to get away. A significant collocate of bushfire is flee (see (17)). In Australia, there has been a policy, often called 'stay or go', whereby those whose houses are threatened by bushfire are advised to either stay and defend their property, or leave early, before it becomes too dangerous to do so (Griffiths 2012). Fleeing is not a safe thing to do; people are advised to leave in an orderly manner in accordance with their bushfire survival plan.

(17) ... killed as they tried to flee the bushfire were Judy Griffith and her grandchildren ...

Some human responses to bushfires can be captured in a cultural script, a simply phrased script composed in NSM conveying a culture's practices and values, as following in $[\mathrm{B}]$.

\section{[B] a cultural script of Australians' response to bushfires}

a. in Australia, many people think like this:

b. people don't want a bushfire to happen in a place because of this, it is good if some people do some things because of this

c. they do some things in this place when a bushfire is not happening because they don't want it to happen

d. when a bushfire happens, they do some other things because they don't want fire to be in this place

they know that they can die when they do these things

they don't want to not do it because of this

e. some people don't want to be in a place where there is a bushfire when it is happening

they want to be in other places, not near places where there is fire, they do some things because of this

when it is like this, it is good if they do these things before the fire is very near the place where they are 
f. after the bushfire happens, some people can do some other things because they want to do something good for the people living in this place

this is good

Component (a) contains the header, similar to those in most cultural scripts. The script is particular to Australia and is widely shared, but not necessarily by all people in the country, so the wording 'many people' is used. Component (b) portrays the desire for a bushfire not to happen in a place, and the cultural evaluation that it is good if some people respond to combat it. These responses follow in components (c) and (d).

In component (c), some people are portrayed as taking steps to prevent bushfire. Component (d) addresses people doing things to combat the fire while it is happening. These actions are with risk (they know they can die when they do these things); however, they still want to do them.

Component (e) depicts people's leaving of areas in which there is a bushfire. It is good if they do this early, before the fire is very near. Component (f) conveys the idea of people doing good things for people affected by fire after it has taken place. This action by people is evaluated as good.

\section{Concluding remarks and prospects for further research}

The chapter has shown that the semantics of bushfire in Australian English encode certain environmental attitudes. The event is conceptualised as bad and destructive to land, creatures, people and the places in which people live. There is same recognition in the sense of bushfire that the vegetation can be expected to burn-semantic content contained within the component 'bush'. In 2003, Arthur outlined how wildfire may replace bushfire for problematic fires in Australian English due to a greater understanding of the necessity of fire for Australian vegetation. This may have happened in a scientific register, but has not come to pass in wider Australian English, as bushfire is still used for problematic fires in the 2010s. The cultural script portraying Australians' responses to bushfire details how Australians value people acting to prevent and combat bushfires, leaving their residences early and helping the affected after the event. 
The cultural script given above is a very general one encompassing a variety of Australians' responses to bushfires. Prospects for continuing research into bushfire and other extreme weather and climate event words include identifying more specific cultural scripts associated with the event. For example, as covered in this script, Australians place value on helping others after natural disasters. A cultural script could be written that details all the surrounding beliefs around this practice. The values elucidated by such a script would be related to the Australian emphasis on mateship and associated ideals, such as the injunction: 'don't abandon a mate' (see Wierzbicka 1997: 101-18, 2002: 1171-72). Australian mateship is the relationship of someone with people thought of as 'like me'. This could help to explain why a critic like Fisher (2011), mentioned previously, sees the practice as excluding racial minorities and the economically disadvantaged.

Australians banding together to fight bushfires and other natural forces has often been connected to the nation uniting to fight a common enemy at war. The official Australian historian of the First World War, C.E.W. Bean, argued that the experience of battling natural forces shaped Australians as soldiers (Sherratt 2005: 3-4). A recruitment poster from 1917 depicts a farmer walking away from a scene in which other men are trying to fight back a fire. The poster asks: 'Would you stand by while a bushfire raged?' and urges 'Get busy and drive the Germans back!' (Weston 1917). This fighting is conceived of as gendered; men have traditionally been responsible for the fighting of both opposing countries and nature. A specific cultural script could be formulated based on notions of many men doing things together in a place because they want something bad not to happen. They know that they could die when they are doing these things, but, despite this, they don't want to not do them. People can think of these men as part of one thing, and they think it is very good if men do these things. In drafting such a script, I would seek not to devalue the contribution women have made to this activity, but capture the still prevailing notion of fighting bushfires as 'men's business' (Eriksen et al. 2010).

Some of the beliefs Australians hold about climate and weather may be culturally ingrained but not necessarily serve them well. Explicitly stating the beliefs and values around extreme weather and the Australian climate allows us to examine them for what they are and, possibly, re-evaluate them. For example, the use of military discourse around individuals battling bushfires has been criticised for contributing to loss of life 
during the 2009 Black Saturday Victorian bushfires. Some people, who may otherwise have left for safety, were led to believe they could stay and defend their houses against what turned out to be unprecedentedly severe bushfires (Griffiths 2012: 163-64). Griffiths writes, 'military metaphors make us believe that we can and must beat fire, somehow. Yet our challenging task as Australians is to learn to live with it' (Griffiths 2012: 164). Griffiths sees such metaphors as a comfort to people because they imply that measures can be taken to stem a powerful natural force.

Metaphors concerned with violence in cancer discourse (such as, 'fought a long battle with leukemia'), too, have been criticised for misleading patients. Yet, they have been found to help sufferers deal with negative emotions, and they are seen as psychologically useful for those with whom they resonate (Semino et al. 2017). Military metaphors may have their drawbacks but may be helpful if used judiciously, as in discourse such as the title of a newspaper article: 'Science fights bushfires on a number of fronts' (Spinks 2014). The article, in part, details how mitigating climate change can reduce the likelihood of bushfire-prone weather.

Further research prospects include examining the idea that some Australian extreme weather event words can be thought of as local cultural keywords rather than Australian cultural keywords. Communities hold high levels of local knowledge about their immediate environments (Foxwell-Norton 2017). Bushfire is built on the Australian English bush, so it may be easier to accept as an Australian cultural keyword than, for example, flood, common to all varieties of English. The word bushfire has a higher degree of salience in the discourse of Victorians than in that of Northern Queenslanders in which cyclone is a more relevant term. The matter requires more investigation and analysis of the senses other words of this kind.

Another fruitful area to explore is the discourse about the relationship between climate change and bushfires. This relationship is becoming more of a part of the Australian consciousness. Yet there is also a discourse opposing this view (Hackett et al. 2017). An entire separate cultural script could be written covering the cultural beliefs behind these conflicting positions. 
The linguistics of extreme weather and climate remains open to exploration. This chapter has shown that detailed semantic analysis of one extreme weather event word bushfire can reveal the cultural and environmental attitudes of Australians.

\section{References}

The Australian National Dictionary (AND) (2016). The Australian National Dictionary: Australian Words and their Origins (2nd edn) (Bruce Moore, Mark Gwynn, Amanda Laugesen and Julia Robinson, eds). Melbourne: Oxford University Press.

Andrews, Avery (2016). Reconciling NSM and formal semantics. Australian Journal of Linguistics 36 (1): 79-111. doi.org/10.1080/07268602.2016.11 09431.

Arthur, Jay (2003). The Default Country: A Lexical Cartography of TwentiethCentury Australia. Sydney: University of New South Wales Press.

AWNRMB-DEWNR (Alinytjara Wilurara Natural Resources Management Board and Department of Environment, Water and Natural Resources) (2014). Alinytjarar Wilurara Fire Management Strategy 2014. Adelaide: Government of South Australia. Available at: www.environment.sa.gov.au/files/sharedassets/ public/fire_management/fire-management-strategy-alinytjara-wiluara-gen.pdf.

Barton, Gregory and Brett Bennett (2013). Environment. In Alison Bashford and Stuart Macintyre (eds), The Cambridge History of Australia. Port Melbourne: Cambridge University Press, 452-71.

Bromhead, Helen (2011). The bush in Australian English. Australian Journal of Linguistics 31 (4): 445-71.

Bromhead, Helen (2018). Landscape and Culture - Cross-linguistic Perspectives. Amsterdam: John Benjamins.

Campbell, Ian (2017). Fire danger signs-Who changes them? What do they mean? about regional. 10 September. Available at: aboutregional.com.au/firedanger-signs-who-changes-them-what-do-they-mean.

Canberra firestorm news coverage [video] (2019). Uploaded 5 August, 2007. Available at: www.youtube.com/watch?v=7UpzyalyUH0. 
Caruana, Patrick (2012). Elvis back in town for hot Vic weekend. Herald Sun. 7 December. Available at: www.heraldsun.com.au/news/breaking-news/ elvis-to-battle-vic-bushfires-again/news-story/99a7080980a0d4e7a312719cf $14 \mathrm{c} 9 \mathrm{aac}$.

CSIRO-BOM (Commonwealth Scientific and Industrial Research Organisation and Bureau of Meteorology) (2018). State of the Climate 2018. Report. Available at: www.csiro.au/ /media/OnA/Files/State-of-the-Climate-2018CSIRO-BOM-Dec2018.pdf.

Doherty, Megan (2008). Lucky charmed city to the end. The Canberra Times. 17 July. Accessed via Factiva. Available at: global-factiva-com.virtual.anu.edu.au/redir/ default.aspx?P=sa\&an=CANBTZ0020080716e47h0001 n\&cat=a\&ep=ASE.

Enfield, N.J. (2008). Linguistic categories and their utilities: The case of Lao landscape terms. Language Sciences 30 (2-3): 227-55. doi.org/10.1016/ j.langsci.2006.12.030.

Eriksen, Christine, Nicholas Gill and Lesley Head (2010). The gendered dimensions of bushfire in changing rural landscapes in Australia. Journal of Rural Studies 26: 332-42. doi.org/10.1016/j.jrurstud.2010.06.001.

Fisher, Naomi (2011). Nationalism and identity in a disaster. $A B C$ News. 20 January. Available at: www.abc.net.au/news/2011-01-20/nationalism_ and_identity_in_a_disaster/43148.

Flanagan, Richard (2019). Tasmania is burning. The climate disaster future has arrived while those in power laugh at us. The Guardian. 5 February. Available at: www.theguardian.com/environment/2019/feb/05/tasmania-is-burning-theclimate-disaster-future-has-arrived-while-those-in-power-laugh-at-us.

Foxwell-Norton, Kerrie (2017). Environmental Communication and Critical Coastal Policy: Communities, Culture and Nature. Abingdon, Oxfordshire: Routledge. doi.org/10.4324/9781315757056.

Gammage, Bill (2011). The Biggest Estate on Earth: How Aborigines Made Australia. Sydney: Allen \& Unwin.

Get Ready Queensland (n.d.). Bushfire. Available at: getready.qld.gov.au/naturaldisasters/bushfire (site discontinued).

Goddard, Cliff(ed.) (2006). Ethnopragmatics: Understanding Discourse in Cultural Context. Berlin: Mouton de Gruyter.

Goddard, Cliff (2010). Semantic molecules and semantic complexity (with special reference to 'environmental' molecules). Review of Cognitive Linguistics 8 (1): 123-55. doi.org/10.1075/ml.8.1.05god. 
Goddard, Cliff and Anna Wierzbicka (2014). Words and Meanings: Lexical Semantics Across Domains, Languages and Cultures. Oxford: Oxford University Press. doi.org/10.1093/acprof:oso/9780199668434.001.0001.

Griffiths, Tom (2012). Remembering. In Christine Hansen and Tom Griffiths (eds), Living with Fire: People, Nature and History in Steels Creek. Collingwood, Victoria: CSIRO Publishing, 159-85. doi.org/10.1071/9780643104808.

Hackett, Robert A., Susan Forde, Shane Gunster and Kerrie Foxwell-Norton (2017). Journalism(s) for climate crisis. In Robert A. Hackett, Susan Forde, Shane Gunster and Kerrie Foxwell-Norton (eds), Journalism and Climate Crisis: Public Engagement, Media Alternatives. Abingdon, Oxon: Routledge. doi.org/10.4324/9781315668734.

Handmer, John and Katharine Haynes (2008). Community Bushfire Safety. Collingwood, Victoria: CSIRO Publishing.

Jaworski, Adam and Crispin Thurlow (2010). Semiotic Landscapes: Language, Image, Space. London: Continuum.

Laskin, David (1996). Braving the Elements: The Stormy History of American Weather. New York: Doubleday.

Leitch, Anne M. and Erin L. Bohensky (2014). Return to 'a new normal': Discourses of resilience to natural disasters in Australian newspapers 20062010. Global Environmental Change 26: 14-26. doi.org/10.1016/j.gloenvcha. 2014.03.006.

Levisen, Carsten and Sophia Waters (eds) (2017a). Cultural Keywords in Discourse. Amsterdam: John Benjamins.

Levisen, Carsten and Sophia Waters (2017b). How words do things with people. In Carsten Levisen and Sophia Waters (eds), Cultural Keywords in Discourse. Amsterdam: John Benjamins, 1-23.

McEnery, Tony and Andrew Hardie (2011). Corpus Linguistics: Method, Theory and Practice. Cambridge: Cambridge University Press.

Morrissey, Shirley A. and Joseph P. Reser (2007). Natural disasters, climate change and mental health considerations for rural Australia. Australian Journal of Rural Health 15: 120-25. doi.org/10.1111/j.1440-1584.2007.00865.x.

Muller, Damon and Colleen Bryant (2008). Understanding and preventing bushfire arson. In John Handmer and Katharine Haynes (eds), Community Bushfire Safety. Collingwood, Victoria: CSIRO Publishing, 99-106. doi.org/ 10.1071/9780643095618. 
Pascoe, Bruce (2014). Dark Emu, Black Seeds: Agriculture or Accident? Broome, Western Australia: Magabala.

Pyne, Stephen J. (2006). The Still-Burning Bush. Melbourne: Scribe.

Rising From The Ashes [film] (2018). Produced by Orsino Images. Indimax Films. Uploaded 12 June 2018. Available at: www.youtube.com/watch?v=FOYR_ SwZ3d4.

Rowan, Roz (2017). Bogan as a keyword of contemporary Australia: Sociality and national discourse in Australian English. In Carsten Levisen and Sophia Waters (eds), Cultural Keywords in Discourse. Amsterdam: John Benjamins, 55-82.

Rudd, Kevin (2009). Nation shows its courage and compassion. The Sydney Morning Herald. 23 February. Available at: www.smh.com.au/national/nationshows-its-courage-and-compassion-20090222-8eq0.html.

Scollon, Ronald and Suzie Wong Scollon (2003). Discourses in Place: Language in the Material World. London: Routledge. doi.org/10.4324/9780203422724.

Semino, Elena, Zsófia Demjén, Andrew Hardie, Sheila Payne and Paul Rayson (2017). Metaphor, Cancer and the End ofLife: A Corpus-Based Study. New York: Routledge. doi.org/10.4324/9781315629834-11.

Sherratt, Tim (2005). Human elements. In Tim Sherratt, Tom Griffiths and Libby Robin (eds), A Change in the Weather: Climate and Culture in Australia. Canberra: National Museum of Australia Press, 1-17.

Sherratt, Tim, Tom Griffiths and Libby Robin (eds) (2005). A Change in the Weather: Climate and Culture in Australia. Canberra: National Museum of Australia Press.

Spinks, Peter (2014). Science fights bushfires on a number of fronts. The Age. 1 December. Available at: www.theage.com.au/education/science-fightsbushfires-on-a-multitude-of-fronts-20141201-11xudb.html.

Webb, Eric K. (ed.) (1997). Windows on Meteorology: Australian Perspective. Collingwood, Victoria: CSIRO Publishing.

West, Brad (2000). Mythologising a natural disaster in post-industrial Australia: The incorporation of Cyclone Tracy within Australian national identity. Journal of Australian Studies 24 (66): 197-204. doi.org/10.1080/ 14443050009387625. 
Weston, Harry J. (1917). [Poster.] NSW Recruiting Committee and Win the War League. Item held at Australian War Memorial, Canberra: item number ARTV00148. Available at: www.awm.gov.au/collection/ARTV00148.

Whetton, Peter (1997). Floods, droughts and the Southern Oscillation connection. In Eric K. Webb (ed.), Windows on Meteorology: Australian Perspective. Collingwood, Victoria: CSIRO Publishing, 180-99.

Wierzbicka, Anna (1985). Lexicography and Conceptual Analysis. Ann Arbor: Karoma.

Wierzbicka, Anna (1986). Does language reflect culture? Evidence from Australian English. Language in Society 15 (3): 349-73. doi.org/10.1017/ s0047404500011805.

Wierzbicka, Anna (1989). Baudouin de Courtenay and the theory of linguistic relativity. In Janusz Rieger, Mieczyslaw Szymczak and Stanislaw Urbanczyk (eds), Jan Niecistaw Baudouin de Courtenay a lingwistyka światowa. Ossolineum: Wroclaw, 51-58.

Wierzbicka, Anna (1992). Semantics, Culture, and Cognition: Universal Human Concepts in Culture-Specific Configurations. New York: Oxford University Press.

Wierzbicka, Anna (1996). Semantics: Primes and Universals. Oxford: Oxford University Press.

Wierzbicka, Anna (1997). Understanding Cultures through their Key Words: English, Russian, Polish, German, and Japanese. New York: Oxford University Press.

Wierzbicka, Anna (2002). Australian cultural scripts-bloody revisited. Journal of Pragmatics 34 (9): 1167-209. doi.org/10.1016/s0378-2166(01)00023-6.

Wierzbicka, Anna (2003 [1991]). Cross-Cultural Pragmatics: The Semantics of Human Interaction (2nd edn). Berlin: Mouton de Gruyter.

Ye, Zhengdao (ed.) (2017). The Semantics of Nouns. Oxford: Oxford University Press. doi.org/10.1093/oso/9780198736721.003.0001. 
This text is taken from Meaning, Life and Culture: In conversation with Anna Wierzbicka, edited by Helen Bromhead and Zhengdao Ye, published 2020 by ANU Press, The Australian National University,

Canberra, Australia.

doi.org/10.22459/MLC.2020.06 